\title{
Pyrophosphatase 1 expression is associated with future recurrence and overall survival in Chinese patients with intrahepatic cholangiocarcinoma
}

\author{
DONGYUN XU ${ }^{1,2^{*}}$, YUQING MIAO ${ }^{3 *}$, XIAOQIANG GU${ }^{4 *}$, JIEJUN WANG ${ }^{3}$ and GUANZHEN YU ${ }^{4}$ \\ ${ }^{1}$ Department of Oncology, Huaihai Hospital Affiliated to Xuzhou Medical University; \\ ${ }^{2}$ Department of Oncology, No. 97 Hospital of The People's Liberation Army, Xuzhou, Jiangsu 221003; \\ ${ }^{3}$ Department of Oncology, Changzheng Hospital, Shanghai 200070; ${ }^{4}$ Department of Oncology, Longhua \\ Hospital Affiliated to Shanghai University of Traditional Chinese Medicine, Shanghai 201203, P.R. China
}

Received July 31, 2016; Accepted December 22, 2017

DOI: $10.3892 /$ ol.2018.8278

\begin{abstract}
The inorganic pyrophosphatase gene (PPA1) encodes inorganic pyrophosphatase, an enzyme that catalyzes the hydrolysis of inorganic pyrophosphate to orthophosphate, and has been revealed to be dysregulated in several types of human cancer. However, the role of PPA1 in intrahepatic cholangiocarcinoma (ICC) has not yet been determined. The present study detected PPA1 expression and investigated its clinical significance in ICC. Tissue microarray blocks containing 93 ICC specimens were constructed. The protein expression of PPA 1 in these specimens was detected by immunohistochemistry. PPA1 was overexpressed in $49.5 \%$ of the ICC specimens and was significantly associated with large tumor size, positive margins, $\mathrm{T}$ stage, lymph nodal metastases, poorly differentiated tumors and advanced disease stage. Furthermore, PPA1 expression was an indicator of future recurrence and poor survival in patients with ICC. Increased expression of PPA1 is a common event in human ICC and is significantly associated with a poor outcome in patients with ICC, suggesting a potential role for PPA1 in the development and progression of ICC.
\end{abstract}

\section{Introduction}

Cholangiocarcinoma includes 3 categories based on the anatomical location of the origin within the biliary system:

Correspondence to: Dr Guanzhen Yu, Department of Oncology, Longhua Hospital Affiliated to Shanghai University of Traditional Chinese Medicine, Building 12, 715 Wanpingsouth Road, Shanghai 201203, P.R. China

E-mail: qiaoshanqian@aliyun.com

*Contributed equally

Key words: intrahepatic cholangiocarcinoma, pyrophosphatase 1, immunohistochemistry, survival analysis, recurrence
Intrahepatic, hilar and distal (1). These malignancies are slow-growing but aggressive and are associated with a very poor prognosis with a median survival of 6-12 months from the point of diagnosis (2). Intrahepatic cholangiocarcinoma (ICC) is the second most common primary hepatic malignancy following hepatocellular carcinoma worldwide, which also has a higher incidence in East Asia $(3,4)$. In recent decades, the incidence and mortality rates of ICC have been progressively increasing $(5,6)$. Curative resection appears to be the most effective treatment for $\operatorname{ICC}(7,8)$. Unfortunately, the resectability rate remains low due to the late presentation of the disease and the invasion of tumor cells into the blood and lymphatic vessels (9). Furthermore, the etiology of ICC remains unknown, as no identifiable risk factors are identified in $90 \%$ of patients with ICC. Predisposing factors include primary hepatolithiasis, sclerosing cholangitis, choledochal cysts, primary biliary cirrhosis and infection with Clonorchis sinensis or Opisthorchis viverrini, as well as inflammatory bowel disease and chronic pancreatitis $(10,11)$. Furthermore, genetic factors regulating the progression and prognosis of ICC remain to be investigated. To date, certain key molecules may aid in diagnosing and predicting the prognosis and future recurrence of ICC (12-14).

The Inorganic pyrophosphatase gene (PPA1) encodes the enzyme, inorganic pyrophosphatase (PPase), which catalyzes the hydrolysis of inorganic pyrophosphate (PPi) to orthophosphate. PPi is a high-energy phosphate compound involved in multiple cell metabolism process, including polysaccharide, nucleic acid and protein synthesis (15). The present study revealed that PPase was associated with the molting and development of roundworm Ascaris (16), and was necessary for the growth of E. coli (17). Additionally, the expression of PPA1 in aging rat liver was higher than that in young rats $(18,19)$. Notably, PPA1 was overexpressed in various types of human tumor, including lung adenocarcinoma, breast cancer, hepatocellular carcinoma and primary colorectal cancer (20-24). However, it remains unclear whether or not PPA1 serves an oncogenic role in ICC, and the mechanisms responsible for this also require further investigation. 
The present study aimed to detect the expression of PPA1 in human resected ICC and to analyze the correlation between PPA1 expression and the malignant behaviors of ICC, in order to predict the outcomes of patients with ICC.

\section{Materials and methods}

Patient specimens and tissue microarray construction. A total of 93 patients with ICC and 25 with benign diseases at the Eastern Hepatobiliary Hospital (Shanghai, China; 75 with ICC and 25 with non-cancerous bile duct tissues) and Changhai Hospital (Shanghai, China; 18 with ICC), between January 2005 and December 2008, were enrolled in the present study. The mean age of these patients was 55 years, ranging from 31 to 79 years. The patient medical records were reviewed to obtain data and detailed information is listed in Table I. Of the enrolled patients, $39(41.9 \%)$ were male and $54(58.1 \%)$ were female, and $51(54.8 \%)$ were diagnosed with stage III/IV disease, while 42 (45.2) exhibited stage I/II disease. All the enrolled patients were available for follow-up and none of the patients had received preoperative treatment, either radiotherapy or chemotherapy.

Tissue microarray blocks of benign diseases and tumor tissue specimens were constructed using a manual arrayer (Beecher Instruments, Sun Prairie, WI, USA). Each block had at least one $1.5-\mathrm{mm}$ core of nonneoplastic mucosal tissue and two $1.5-\mathrm{mm}$ cores of primary tumor tissue (25). All the tissue specimens in the present study were obtained with written informed consent and the use of the tissues and clinical information was approved by the Eastern Hepatobiliary Hospital and Changhai Hospital Institutional Review Boards.

Immunohistochemistry and evaluation of immunostaining. 4- $\mu \mathrm{m}$ thick sections of the paraffin-embedded tissue microarrays (TMAs) were deparaffinized in xylene, and then rehydrated in graded concentrations of ethyl alcohol $(100,95,75 \%)$, then water. TMA sections were microwave-treated in $0.01 \mathrm{~mol} / 1$ citrate buffer $(\mathrm{pH} \mathrm{6.0)}$ at $99^{\circ} \mathrm{C}$ for $4 \mathrm{~min}$. TMAs were placed in $3 \% \mathrm{H}_{2} \mathrm{O}_{2}$ for $10 \mathrm{~min}$ to inhibit endogenous peroxide activity, washed 3 times with phosphate-buffered saline (PBS) for 3 min and blocked in goat serum (SP KIT-B1 Fuzhou Maixin Biotechnology Development Co., Ltd., Fuzhou, China) at room temperature for $10 \mathrm{~min}$. Anti-PPA1 primary antibody (cat. no. H62; dilution, 1:100; Santa Cruz Biotechnology, Inc., Dallas, TX, USA), was incubated with the sections for at $4^{\circ} \mathrm{C}$ for $24 \mathrm{~h}$. TMAs were then washed 3 times with PBS buffer for $10 \mathrm{~min}$. A streptavidin-peroxidase kit (cat. no. KIT-9720; Maixin Biotech Co., Ltd., Fuzhou, China) was used to visualize antibody binding, according to the manufacturer's instructions. The sections were counterstained with hematoxylin for $3 \mathrm{~min}$ at room temperature and washed in water for $3 \mathrm{~min}$. These TMAs were rehydrated in a descending series of alcohol (85, 95, and 100\%; $2 \mathrm{~min}$ each) and Xylene for $1 \mathrm{~min}$. A semiquantitative scoring system was used to evaluate the expression of PPA1 under an Olympus CX31 microscope (Olympus, Center Valley, PA, USA), as previously described (26). A light microscope was used at a magnification is of $\mathrm{x} 40$ or x200. Staining intensity was divided into: Negative, 0; weak, 1 ; moderate, 2 ; and intense, 3 . The percentage of positively
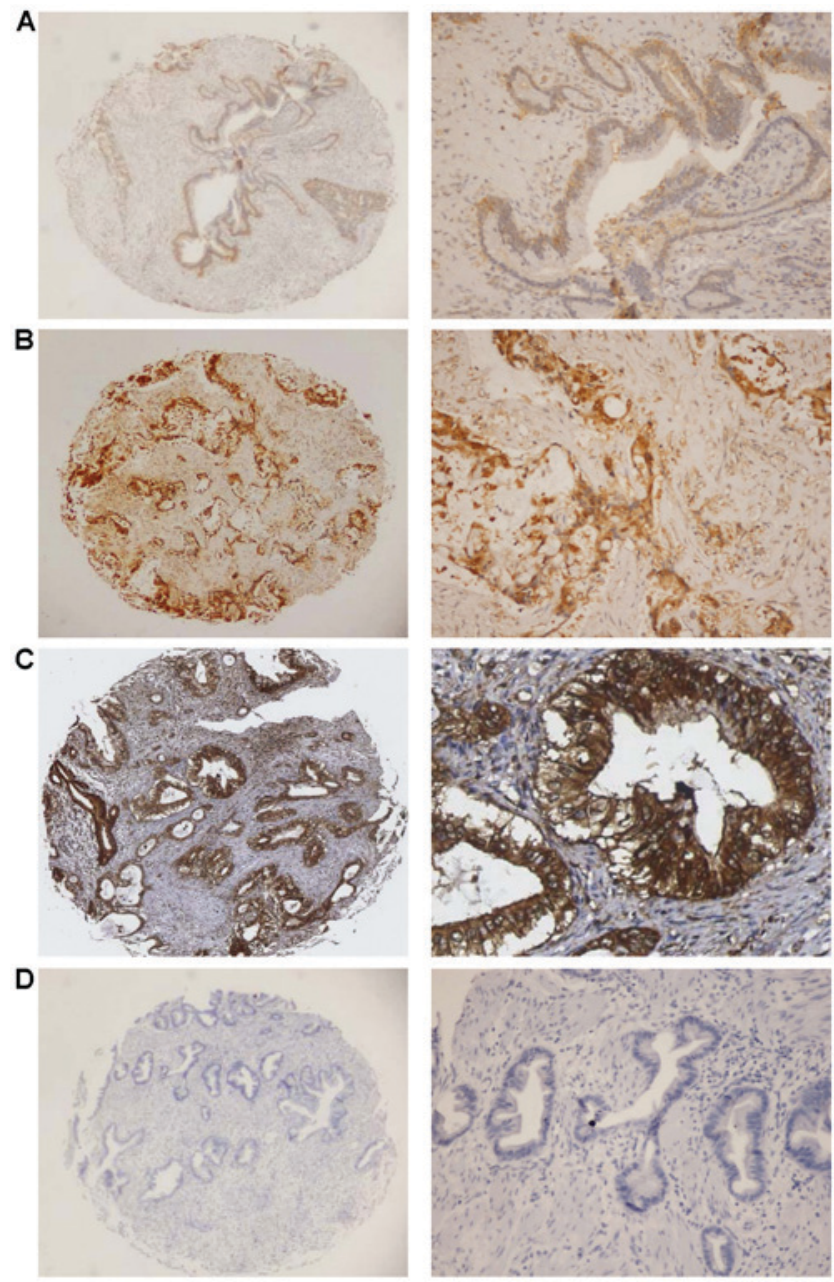

Figure 1. Immunohistochemical staining of PPA1 in intrahepatic cholangiocarcinoma and non-neoplastic bile ducts. (A) Non-neoplastic bile ducts Positive expression of PPA1 in (B) poorly- and (C) moderately-differentiated tumors. (D) Negative expression of PPA1. Original magnifications were as follows: Left, x40; and right, x200. PPA1, inorganic pyrophosphatase.

stained cells was scored as $0-1(0-100 \%)$. Theoretically, a weighted score ranging between 0 ( $0 \%$ of cells stained) and 3 ( $100 \%$ of the cells stained at $3+$ intensity) was generated for each case. A score $>0$ was considered as positive.

Statistical analysis. Categorical data were analyzed using the $\chi^{2}$ test. Survival rates were calculated using the Kaplan-Meier method. The Cox proportional hazards model for multivariate survival analysis was used to assess predictors associated with tumor recurrence and survival. $\mathrm{P}<0.05$ was considered to indicate a statistically significant difference. Statistical analyses and graphics were performed using the SPSS 19.0 statistical package (IBM Corp., Armonk, NY, USA) (27).

\section{Results}

Expression of PPAl in patients with ICC. Representative images of PPA1 immunostaining in human ICC and paired adjacent non-neoplastic tissues are presented in Fig. 1. No staining or weak staining of PPA1 $(21.7 \% ; 5 / 23)$ was observed in the cytoplasm of cholangiocytes of normal bile ducts and benign diseases (Fig. 1A). In tumor cells, however, strong 
Table I. Correlation between PPA1 expression and clinicopathological parameters of intrahepatic cholangiocarcinoma.

\begin{tabular}{lccc}
\hline Variable & $\mathrm{n}$ & PPA1 positive $(\%)$ & P-value \\
\hline Age, years & & & \\
$\quad \leq 60$ & 69 & $29(42.0)$ & 0.015 \\
$>60$ & 24 & $17(70.8)$ & \\
Sex & & & \\
Male & 39 & $21(53.8)$ & 0.472 \\
Female & 54 & $25(46.3)$ & \\
Tumor size, cm & & & \\
$\leq 3$ & 34 & $9(26.5)$ & 0.001 \\
$>3$ & 59 & $37(62.7)$ & \\
Positive margin & & & 0.004 \\
No & 58 & $22(37.9)$ & \\
Yes & 35 & $24(68.6)$ & \\
T stage & & & 0.001 \\
T1/T2 & 31 & $5(16.1)$ & \\
T3/T4 & 62 & $41(66.1)$ & \\
Lymph node metastasis & & & \\
No & 42 & $13(31.0)$ & 0.001 \\
Yes & 51 & $33(64.7)$ & \\
Differentiation & & & \\
Well/moderately & 77 & $32(41.6)$ & \\
Poorly & 16 & $14(87.5)$ & \\
TNM & & & \\
I/II & 42 & $13(31.0)$ & \\
III/IV & 51 & $33(64.7)$ & \\
\hline
\end{tabular}

PPA1, inorganic pyrophosphatase; T, tumor; TNM, Tumor-NodeMetastasis.

PPA1-positive staining was preferentially localized to the cytoplasm. Positive expression of PPA1 was observed in 46/93 $(49.5 \%)$ of the primary ICC tissues (Fig. 1B-D).

Correlation between PPA1 expression and clinicopathological parameters in ICC. A statistically significant correlation was observed between PPA1 expression and age, tumor size, positive margin and histology (Table I). Of the 24 patients aged $>60$ years, 17 (70.8\%) exhibited positive PPA1 expression, while only $29 / 69(42.0 \%)$ patients aged $\leq 60$ years exhibited positive PPA1 expression $(\mathrm{P}=0.015)$. Of the 59 patients with a tumor size $>3 \mathrm{~cm}, 37(62.7 \%)$ presented with PPA1 expression, while only $9(26.5 \%)$ of 34 cases with a tumor size $\leq 3 \mathrm{~cm}$ presented with PPA1 expression $(\mathrm{P}=0.001)$. Of the 58 cases with negative tumor margins, 22 (37.9\%) exhibited positive PPA1 expression while $24(68.6 \%)$ of the 35 cases with positive tumor margins exhibited positive PPA1 expression. Of the 16 patients with poorly-differentiated tumors, $14(87.5 \%)$ exhibited positive PPA1 expression; whereas of the 77 patients with well-differentiated to moderately-differentiated tumors, only $32(41.6 \%)$ exhibited positive PPA1 expression $(\mathrm{P}=0.001)$.
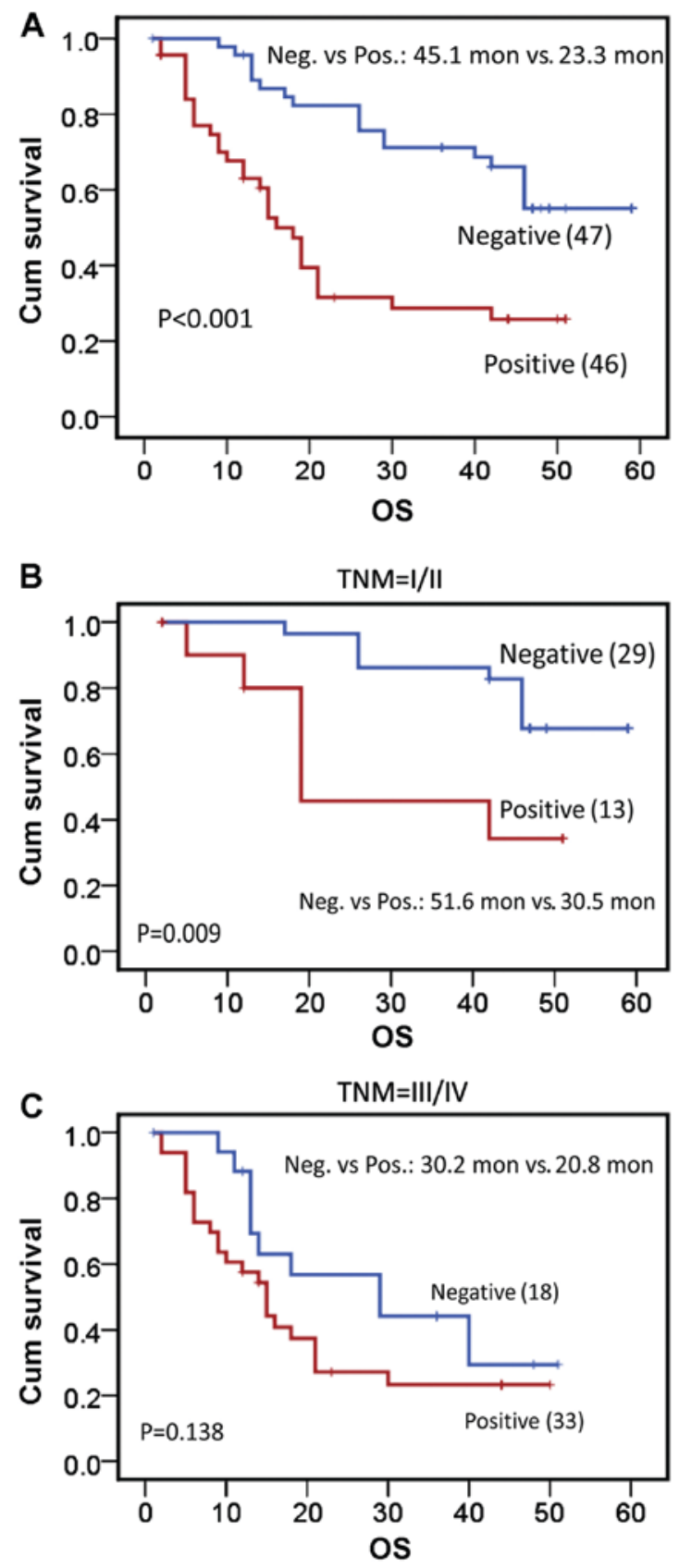

Figure 2. Kaplan-Meier analysis of the OS in patients with ICC according to the expression of PPA1. (A) OS were significantly shorter in patients with positive PPA1 expression (median survival, 23.3 months) than in those with negative PPA1 (median survival, 45.1 months; $\mathrm{P}<0.001$ ). (B) OS were significantly shorter in patients exhibiting stage I/II disease with positive PPA1 expression (median survival, 30.5 months) than in those with negativePPA1 expression (median survival, 51.6 months; $\mathrm{P}=0.009$ ). (C) OS were shorter in patients exhibiting stage III/IV disease with positive PPA1 expression (median survival, 20.8 months) than in thosewith negative PPA1 expression, but with no statistical significance (median survival, 30.2 months; $\mathrm{P}=0.138$ ). OS, overall survival; ICC, intrahepatic cholangiocarcinoma; PPA1, inorganic pyrophosphatase; TNM, Tumor-Node-Metastasis.

Furthermore, it was also revealed that overexpression of PPA1 was correlated with advanced tumor $(\mathrm{T})$, node $(\mathrm{N})$, and Tumor-Node-Metastasis (TNM) stages according to the 8th edition AJCC staging manual (28). Positive PPA1 expression was observed more frequently in large ICC tumors (invasion level T3-T4) (66.1\%) than in small ICC tumors (invasion level T1-T2; $16.1 \%$; $\mathrm{P}<0.001)$, and more frequently in cases with regional 
Table II. Univariate and multivariate analysis of variables associated with overall survival in patients with intrahepatic cholangiocarcinoma.

\begin{tabular}{|c|c|c|c|c|c|c|}
\hline \multirow[b]{2}{*}{ Variable } & \multirow[b]{2}{*}{$\mathrm{n}$} & \multirow{2}{*}{$\begin{array}{l}\text { Mean survival, } \\
\text { months }\end{array}$} & \multicolumn{2}{|c|}{ P-value } & \multirow[b]{2}{*}{ Hazard ratio } & \multirow[b]{2}{*}{$95 \% \mathrm{CI}$} \\
\hline & & & Univariate & Multivariate & & \\
\hline \multicolumn{7}{|l|}{ Sex } \\
\hline Male & 39 & 25.8 & $<0.001$ & & & \\
\hline Female & 54 & 42.0 & & & & \\
\hline \multicolumn{7}{|l|}{ Tumor size, $\mathrm{cm}$} \\
\hline$\leq 3$ & 34 & 42.5 & 0.008 & & & \\
\hline$>3$ & 59 & 29.0 & & & & \\
\hline \multicolumn{7}{|l|}{ Positive margin } \\
\hline No & 58 & 43.2 & $<0.001$ & & & \\
\hline Yes & 35 & 21.8 & & & & \\
\hline \multicolumn{7}{|l|}{$\mathrm{T}$ stage } \\
\hline $\mathrm{T} 1 / \mathrm{T} 2$ & 31 & 53.2 & $<0.001$ & 0.01 & 0.240 & $0.080-0.715$ \\
\hline $\mathrm{T} 3 / \mathrm{T} 4$ & 62 & 24.9 & & & & \\
\hline \multicolumn{7}{|c|}{ Regional lymph nodes positive } \\
\hline No & 42 & 47.2 & $<0.001$ & 0.055 & 0.477 & $0.224-1.017$ \\
\hline Yes & 51 & 24.3 & & & & \\
\hline \multicolumn{7}{|l|}{ TNM stage } \\
\hline $\mathrm{I} / \mathrm{II}$ & 42 & 47.2 & $<0.001$ & 0.055 & 0.477 & $0.224-1.017$ \\
\hline III/IV & 51 & 24.3 & & & & \\
\hline \multicolumn{7}{|l|}{ PPA1 } \\
\hline Negative & 47 & 45.1 & $<0.001$ & & & \\
\hline Positive & 46 & 23.3 & & & & \\
\hline \multicolumn{7}{|l|}{ Differentiation } \\
\hline Well/moderately & 77 & 39.0 & $<0.001$ & & & \\
\hline Poorly/undifferentiated & 16 & 17.7 & & & & \\
\hline
\end{tabular}

CI, confidence interval; T, tumor; TNM, Tumor-Node-Metastasis; PPA1, inorganic pyrophosphatase.

lymph node metastasis $(64.7 \%)$ than in N0-stage tumors $(31.0 \%$; $\mathrm{P}=0.001)$. With regards to the TNM stage, overexpression of PPA1 was significantly associated with advanced disease stages: $31 \%$ at stage I/II and $64.7 \%$ at stage III/IV $(\mathrm{P}=0.001)$.

PPA1 expression is associated with decreased overall survival $(O S)$ in patients with ICC. The median cumulative overall survival in patients with resected ICC was 33 months. Kaplan-Meier analyses revealed that the ICC patients with positive PPA1 expression had a poor prognosis compared with those with negative PPA1 expression ( $\mathrm{P}<0.001$; Fig. 2A). Furthermore, subgroup analysis of PPA1 expression according to TNM stage was performed. The outcome of patients with PPA1-positive expression was worse in those with stage I/II disease than in those without PPA1 expression with stage I/II disease (51.6 vs. 30.5 months; $\mathrm{P}=0.009$; Fig. $2 \mathrm{~B}$ ). In patients with stage III/IV disease, patients with PPA1-positive expression tended to have a worse outcome than those without PPA1 expression, but this difference was no statistically significant (30.2 vs. 20.8 months; $\mathrm{P}=0.138$; Fig. 2C). Additionally, univariate analysis revealed that all other factors were significantly associated with patient overall survival (Table II), including gender $(\mathrm{P}<0.001)$, tumor size $(\mathrm{P}=0.008)$, positive tumor margins $(\mathrm{P}<0.001)$, $\mathrm{T}$ stage $(\mathrm{P}<0.001)$, regional lymph node metastasis $(\mathrm{P}<0.001)$, TNM stage $(\mathrm{P}<0.001)$ and differentiation $(\mathrm{P}<0.001)$. Subsequent multivariate analysis using the Cox proportional hazards model demonstrated that $\mathrm{T}$ stage was an independent prognostic indicator of OS in patients with ICC (Table II).

PPAl expression is associated with recurrence in patients with ICC. Among the 93 patients with ICC, 90 experienced recurrence following resection. Patients with PPA1-positive tumors exhibited higher chanceto recurrence compared with those with PPA1-negative tumors $(\mathrm{P}<0.001$; Fig. $3 \mathrm{~A})$. Furthermore, in patients with stage I/II disease, Kaplan-Meier survival analyses according to TNM stage revealed that those with PPA1-negative tumors exhibited a significantly longer disease-free survival (DFS) than those with PPA1-positive tumors (50.2 vs. 26.7 months; $\mathrm{P}=0.008$; Fig. 3B). However, this difference was not statistically significant in patients with stage III/IV disease (PPA1-negative vs. PPA1-positive: 27.5 vs. 19.6 months; $\mathrm{P}=0.184$; Fig. $3 \mathrm{C}$ ). In addition, the univariate 
Table III. Univariate and multivariate analysis of variables associated with recurrence in patients with intrahepatic cholangiocarcinoma.

\begin{tabular}{|c|c|c|c|c|c|c|}
\hline \multirow[b]{2}{*}{ Variable } & \multirow[b]{2}{*}{ no. } & \multirow[b]{2}{*}{ Mean survival, months } & \multicolumn{2}{|c|}{ P-value } & \multirow[b]{2}{*}{ Hazard ratio } & \multirow[b]{2}{*}{$95 \% \mathrm{CI}$} \\
\hline & & & Univariate & Multivariate & & \\
\hline \multicolumn{7}{|l|}{ Age, years } \\
\hline$\leq 60$ & 66 & 38.2 & 0.011 & & & \\
\hline$>60$ & 24 & 25.6 & & & & \\
\hline \multicolumn{7}{|l|}{ Sex } \\
\hline Male & 36 & 25.1 & 0.005 & & & \\
\hline Female & 54 & 39.8 & & & & \\
\hline \multicolumn{7}{|l|}{ Tumor size, cm } \\
\hline$\leq 3$ & 31 & 44.2 & 0.003 & & & \\
\hline$>3$ & 59 & 26.8 & & & & \\
\hline \multicolumn{7}{|l|}{ Positive margin } \\
\hline No & 58 & 42.0 & $<0.001$ & & & \\
\hline Yes & 32 & 19.2 & & & & \\
\hline \multicolumn{7}{|l|}{ T stage } \\
\hline $\mathrm{T} 1 / \mathrm{T} 2$ & 31 & 52.5 & $<0.001$ & 0.004 & 0.208 & $0.072-0.601$ \\
\hline $\mathrm{T} 3 / \mathrm{T} 4$ & 59 & 23.2 & & & & \\
\hline \multicolumn{7}{|c|}{ Regional lymph nodes positive } \\
\hline No & 42 & 44.8 & $<0.001$ & & & \\
\hline Yes & 48 & 22.7 & & & & \\
\hline \multicolumn{7}{|l|}{ TNM stage } \\
\hline $\mathrm{I} / \mathrm{II}$ & 42 & 44.8 & $<0.001$ & & & \\
\hline III/IV & 48 & 22.7 & & & & \\
\hline \multicolumn{7}{|l|}{ PPA1 } \\
\hline Negative & 47 & 42.9 & $<0.001$ & $<0.001$ & 0.302 & $0.112-0.651$ \\
\hline Positive & 43 & 22.2 & & & & \\
\hline \multicolumn{7}{|l|}{ Differentiation } \\
\hline Well/moderately & 74 & 38.7 & $<0.001$ & 0.006 & 0.313 & $0.137-0.711$ \\
\hline Poor/undifferentiated & 16 & 14.7 & & & & \\
\hline
\end{tabular}

CI, confidence interval; T, tumor; TNM, Tumor-Node-Metastasis; PPA1, inorganic pyrophosphatase.

analysis revealed that age $(\mathrm{P}=0.011)$, sex $(\mathrm{P}=0.005)$, tumor size $(\mathrm{P}=0.003)$, positive margin $(\mathrm{P}<0.001)$, $\mathrm{T}$ stage $(\mathrm{P}<0.001)$, lymph node metastasis $(\mathrm{P}<0.001)$, disease stage $(\mathrm{P}<0.001)$ and differentiation $(\mathrm{P}<0.001)$ were significant predictors of tumor recurrence (Table III). Multivariate analysis using the Cox proportional hazards model demonstrated that PPA1 expression, $\mathrm{T}$ stage and differentiation were independent predictors of tumor recurrence (Table III).

\section{Discussion}

The expression profile of the PPA1 gene has been investigated in lung adenocarcinoma, breast cancer, hepatocellular carcinoma, primary colorectal cancer and gastric cancer, and the PPA1 protein has been revealed to be overexpressed in these types of cancer (20-24,29). Given that ICC has a high mortality rate worldwide and that early tumor invasion, wide metastases and recurrence result in a poor prognosis for patients with this disease (2), the present study aimed to investigate the potential role of PPA1 in ICC. It was revealed that PPA1 was highly overexpressed in ICC specimens compared with expression in adjacent non-neoplastic tissues and benign disease tissues, and overexpression of PPA1 was significantly correlated with malignant behaviors of ICC including tumor size, tumor margins, $\mathrm{T}$ stage, lymph node metastasis, differentiation and TNM stage. Additionally, patients with PPA1-overexpression exhibited poorer OS rates and higher rates of recurrence than patients with low PPA1 expression. Therefore, to the best of our knowledge, these data serve as the first evidence that PPA1 may serve an important role in ICC development and progression.

A number of previous studies have examined clinicopathological prognostic factors for ICC following surgical resection, including sex, age at diagnosis, tumor size, tumor margins, depth of tumor invasion, differentiation, lymph node metastasis and TNM stage (30-33). Furthermore, it was well-known that lymph 


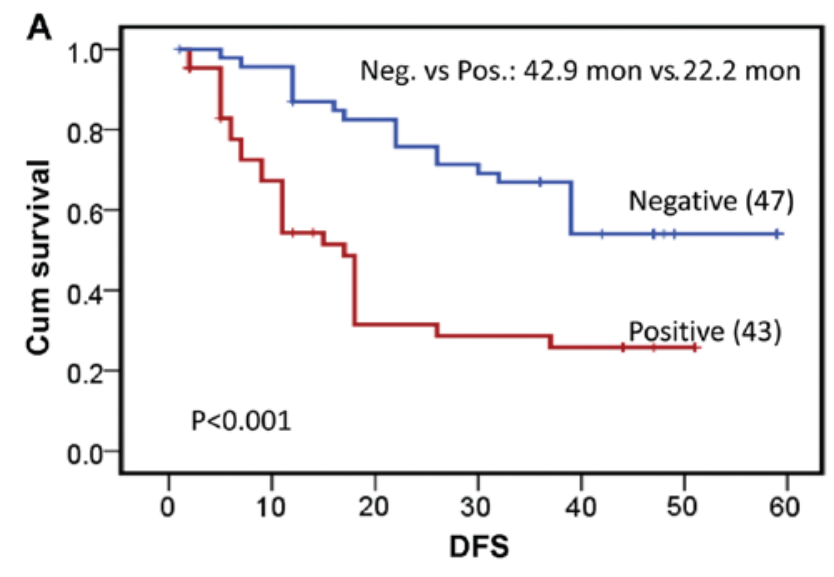

B

TNM $=1 / 11$

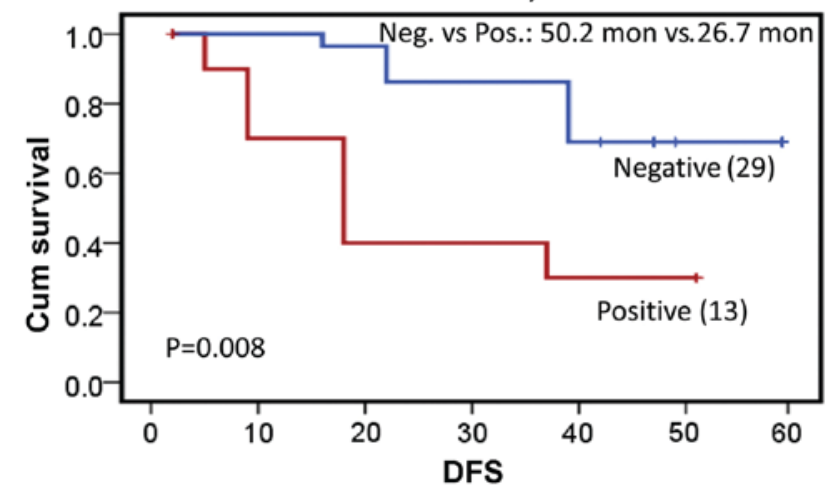

C

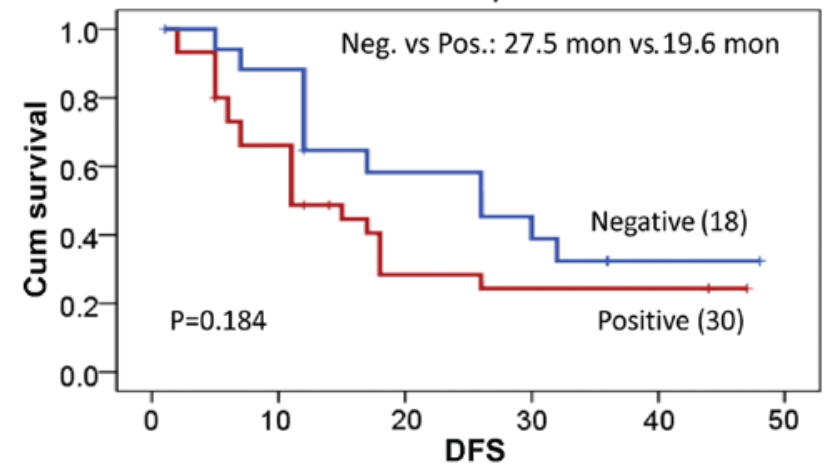

Figure 3. Kaplan-Meier of DFS in patients with ICC according to the expression of PPA1. (A) DFS were significantly shorter in patients with positive PPA1 (median survival, 22.2 months) than in those with negative PPA1 expression (median survival, 42.9 months; $\mathrm{P}<0.001$ ). (B) DFS were significantly shorter in patients exhibiting stage I/II disease with positive PPA1 expression (median survival, 26.7 months) than in those with negative PPA1 expression (median survival, 50.2 months; $\mathrm{P}=0.008$ ). (C) DFS were shorter in patients exhibiting III/IV stage disease with positive PPA1 expression (median survival, 19.6 months) than in those with negative PPA1 expression, but with no statistical significance (median survival, 27.5 months; $\mathrm{P}=0.184$ ). DFS, disease-free survival; ICC, intrahepatic cholangiocarcinoma; PPA1, inorganic pyrophosphatase; TNM, Tumor-Node-Metastasis.

node metastases, TNM stage and tumor margins are important indicators for predicting tumor recurrence and OS $(31,33)$. In the present study, it was revealed that age, sex, tumor size, tumor margins, T stage, lymph node metastasis, differentiation, TNM stage and PPA1 expression levels were predictors of survival in a group of Chinese patients with ICC. Additionally, T stage was revealed to be an independent predictor of OS. Additionally, tumor recurrence, $\mathrm{T}$ stage, PPA1 and differentiation may predict future recurrence independently. Notably, only in the relatively early disease stages, patients with positive PPA1 expression experienced significantly shorter OS and higher recurrence rates than those with negative PPA1 expression, indicating that early detection may be an effective way to prolong the outcome of patients with ICC.

It is known that poorly-differentiated tumors proliferate and metastasize more frequently than well-differentiated tumors. In the present study, PPA1 was expressed more frequently in poorly-differentiated tumors than in well/moderately-differentiated tumors. In addition, positive PPA1 expression was observed more frequently at late stages than at early stages of the disease, suggesting that PPA1 may serve an important role in promoting the growth and development of ICC. However, there are several limitations to the present study. To begin with, the number of ICC samples was small. Additionally, the underlying molecular mechanisms of PPA1 in ICC progression and prognosis were not thoroughly investigated. However, it may be concluded that PPA1 may serve an important role in ICC by regulating energy metabolism and signaling pathways $(34,35)$.

In summary, the present study demonstrated that PPA1 was overexpressed in human ICC and that the level of PPA1 expression may be associated with adverse clinical outcomes in patients with ICC. Furthermore, overexpression of PPA1 was a promising prognostic and predictive factor in Chinese patients with ICC. These observations support PPA1 as an indicator of a worse outcome for patients with ICC and as a potential biomarker in predicting the outcome of patients.

\section{Acknowledgements}

The authors would like to thank Professor Wenlong Yu from Eastern Hepatobiliary Hospital and and Dr Ying Chen from Changhai Hospital for providing the tumor specimens. The present study was supported in part by the Shanghai Pujiang Program (grant no. 13PJD002), the National Natural Science Foundation of China (grant no. 81572856) and the International S\&T Cooperation Program of China (grant no. 2014DFA33010).

\section{Competing interests}

The authors declare that they have no competing interests.

\section{References}

1. Razumilava N and Gores GJ: Cholangiocarcinoma. Lancet 383: 2168-2179, 2014.

2. Nehls O, Gregor M and Klump B: Serum and bile markers for cholangiocarcinoma. Semin Liver Dis 24: 139-154, 2004.

3. Patel T: Increasing incidence and mortality of primary intrahepatic cholangiocarcinoma in the United States. Hepatology 33: 1353-1357, 2001.

4. Patel T: Worldwide trends in mortality from biliary tract malignancies. BMC Cancer 2: 10, 2002.

5. Poultsides GA, Zhu AX, Choti MA and Pawlik TM: Intrahepatic cholangiocarcinoma. Surg Clin North Am 90: 817-837, 2010.

6. Cardinale V, Carpino G, Reid L, Gaudio E and Alvaro D: Multiple cells of origin in cholangiocarcinoma underlie biological, epidemiological and clinical heterogeneity. World J Gastrointest Oncol 4: 94-102, 2012.

7. Harrison LE, Fong Y, Klimstra DS, Zee SY and Blumgart LH: Surgical treatment of 32 patients with peripheral intrahepatic cholangiocarcinoma. Br J Surg 85: 1068-1070, 1998. 
8. Yamamoto M, Takasaki K, Yoshikawa T, Ueno K and Nakano M Does gross appearance indicate prognosis in intrahepatic cholangiocarcinoma? J Surg Oncol 69: 162-167, 1998.

9. Nakagohri T, Kinoshita T, Konishi M, Takahashi S and Gotohda N: Surgical outcome and prognostic factors in intrahepatic cholangiocarcinoma. World J Surg 32: 2675-2680, 2008.

10. El-Serag HB, Engels EA, Landgren O, Chiao E, Henderson L, Amaratunge $\mathrm{HC}$ and Giordano TP: Risk of hepatobiliary and pancreatic cancers after hepatitis $\mathrm{C}$ virus infection: A population-based study of U.S. veterans. Hepatology 49: 116-123, 2009.

11. Welzel TM, Graubard BI, El-Serag HB, Shaib YH, Hsing AW, Davila JA and McGlynn KA: Risk factors for intrahepatic and extrahepatic cholangiocarcinoma in the United States: A population-based case-control study. Clin Gastroenterol Hepatol 5: 1221-1228, 2007.

12. Zhang F, Li L, Yang X, Wang B, Zhao J, Lu S and Yu X: Expression and activation of EGFR and STAT3 during the multistage carcinogenesis of intrahepatic cholangiocarcinoma induced by 3'-methyl-4 dimethylaminoazobenzene in rats. J Toxicol Pathol 28: 79-87, 2015.

13. Chen Y, Ma L, He Q, Zhang S, Zhang C and Jia W: TGF- $\beta 1$ expression is associated with invasion and metastasis of intrahepatic cholangiocarcinoma. Biol Res 48: 26, 2015.

14. Tian X, Wang Q, Li Y, Hu J, Wu L, Ding Q and Zhang C: The expression of S100A4 protein in human intrahepatic cholangiocarcinoma: Clinicopathologic significance and prognostic value. Pathol Oncol Res 21: 195-201, 2015.

15. Baykov AA, Cooperman BS, Goldman A and Lahti R: Cytoplasmic inorganic pyrophosphatase. Prog Mol Subcell Biol 23: 127-150, 1999.

16. Islam MK, Miyoshi T, Yamada M and Tsuji N: Pyrophosphatase of the roundworm Ascaris suum plays an essential role in the worm's molting and development. Infect Immun 73: 1995-2004, 2005

17. Chen J, Brevet A, Fromant M, Lévêque F, Schmitter JM, Blanquet S and Plateau P: Pyrophosphatase is essential for growth of Escherichia coli. J Bacteriol 172: 5686-5689, 1990.

18. Kharbhih WJ and Sharma R: Age-dependent increased expression and activity of inorganic pyrophosphatase in the liver of male mice and its further enhancement with short- and long-term dietary restriction. Biogerontology 15: 81-86, 2014.

19. Panda H, Pandey RS, Debata PR and Supakar PC: Age-dependent differential expression and activity of rat liver cytosolic inorganic pyrophosphatase gene. Biogerontology 8: 517-525, 2007.

20. Chen G, Gharib TG, Huang CC, Thomas DG, Shedden KA, Taylor JM, Kardia SL, Misek DE, Giordano TJ, Iannettoni MD, et al: Proteomic analysis of lung adenocarcinoma: Identification of a highly expressed set of proteins in tumors. Clin Cancer Res 8: 2298-2305, 2002.

21. Hamler RL, Zhu K, Buchanan NS, Kreunin P, Kachman MT, Miller FR and Lubman DM: A two-dimensional liquid-phase separation method coupled with mass spectrometry for proteomic studies of breast cancer and biomarker identification. Proteomics 4: 562-577, 2004.

22. Chahed K, Kabbage M, Ehret-Sabatier L, Lemaitre-Guillier C, Remadi S, Hoebeke J and Chouchane L: Expression of fibrinogen E-fragment and fibrin E-fragment is inhibited in the human infiltrating ductal carcinoma of the breast: The two-dimensional electrophoresis and MALDI-TOF-mass spectrometry analyses. Int J Oncol 27: 1425-1431, 2005.
23. Megger DA, Bracht T, Kohl M, Ahrens M, Naboulsi W, Weber F, Hoffmann AC, Stephan C, Kuhlmann K, Eisenacher M, et al: Proteomic differences between hepatocellular carcinoma and nontumorous liver tissue investigated by a combined gel-based and label-free quantitative proteomics study. Mol Cell Proteomics 12: 2006-2020, 2013.

24. Tomonaga T, Matsushita K, Yamaguchi S, Oh-Ishi M, Kodera Y, Maeda T, Shimada H, Ochiai T and Nomura F: Identification of altered protein expression and post-translational modifications in primary colorectal cancer by using agarose two-dimensional gel electrophoresis. Clin Cancer Res 10: 2007-2014, 2004.

25. Yu WL, Cong WM, Zhang Y, Chen Y, Wang F and Yu G Overexpression of ATA1/SLC38A1 predicts future recurrence and death in Chinese patients with hilar cholangiocarcinoma. J Surg Res 171: 663-668, 2011.

26. Chen Y, Cha Z, Fang W, Qian B, Yu W, Li W, Yu G and Gao Y: The prognostic potential and oncogenic effects of PRR11 expression in hilar cholangiocarcinoma. Oncotarget 6: 20419-20433, 2015.

27. Yu G, Yu W, Jin G, Xu D, Chen Y, Xia T, Yu A, Fang W, Zhang X, $\mathrm{Li} \mathrm{Z}$ and Xie K: PKM2 regulates neural invasion of and predicts poor prognosis for human hilar cholangiocarcinoma. Mol Cancer 14: 193, 2015.

28. Kim Y, Moris DP, Zhang XF, Bagante F, Spolverato G, Schmidt C, Dilhoff M and Pawlik TM: Evaluation of the 8th edition American joint commission on cancer (AJCC) staging system for patients with intrahepatic cholangiocarcinoma: A surveillance, epidemiology, and end results (SEER) analysis. J Surg Oncol 116: 643-650, 2017.

29. Jeong SH, Ko GH, Cho YH, Lee YJ, Cho BI, Ha WS, Choi SK, Kim JW, Lee CW, Heo YS, et al: Pyrophosphatase overexpression is associated with cell migration, invasion, and poor prognosis in gastric cancer. Tumour Biol 33: 1889-1898, 2012.

30. Sempoux C, Jibara G, Ward SC, Fan C, Qin L, Roayaie S, Fiel MI, Schwartz $M$ and Thung SN: Intrahepatic cholangiocarcinoma: New insights in pathology. Semin Liver Dis 31: 49-60, 2011.

31. Hyder O, Marques H, Pulitano C, Marsh JW, Alexandrescu S, Bauer TW, Gamblin TC, Sotiropoulos GC, Paul A, Barroso E, et al: A nomogram to predict long-term survival after resection for intrahepatic cholangiocarcinoma: An Eastern and Western experience. JAMA Surg 149: 432-438, 2014.

32. Ribero D, Pinna AD, Guglielmi A, Ponti A, Nuzzo G, Giulini SM, Aldrighetti L, Calise F, Gerunda GE, Tomatis M, et al: Surgical approach for long-term survival of patients with intrahepatic cholangiocarcinoma: A multi-institutional analysis of 434 patients. Arch Surg 147: 1107-1113, 2012.

33. Li YY, Li H, Lv P, Liu G, Li XR, Tian BN and Chen DJ: Prognostic value of cirrhosis for intrahepatic cholangiocarcinoma after surgical treatment. J Gastrointest Surg 15: 608-613, 2011.

34. Mishra DR, Chaudhary S, Krishna BM and Mishra SK: Identification of critical elements for regulation of inorganic pyrophosphatase (PPA1) in MCF7 breast cancer cells. PLoS One 10: e0124864, 2015.

35. Thoma I, Loeffler C, Sinha AK, Gupta M, Krischke M, Steffan B, Roitsch T and Mueller MJ: Cyclopentenone isoprostanes induced by reactive oxygen species trigger defense gene activation and phytoalexin accumulation in plants. Plant $\mathbf{J} 34$ : 363-375, 2003 . 